\title{
Crónica de las IV Jornadas constitucionales: Constitución, Urbanismo y Vivienda
}

\author{
Carmen de Guerrero Manso* \\ Universidad de Zaragoza
}

I. Durante los días 13 y 14 de diciembre de 2006 tuvieron lugar las «IV Jornadas constitucionales» organizadas por la Facultad de Derecho de la Universidad de Zaragoza y El Justicia de Aragón en las que se abordó, tal y como anunciaba su título — «Constitución, Urbanismo y Vivienda»—, la compleja materia de la efectividad del derecho a una vivienda digna y adecuada en España y las diversas medidas que, en aras a facilitar su consecución, pueden adoptar los poderes públicos.

El sustrato común de las distintas intervenciones fue la necesidad de trascender la perspectiva meramente jurídica del urbanismo, aunando el estudio del Derecho con el de otras disciplinas, tales como la sociología, la economía o el medioambiente, ya que sólo así será viable el objetivo de crear ciudades sostenibles y dotadas de un adecuado grado de calidad.

Esta perspectiva integradora constituyó la esencia de la primera ponencia de la jornada, a cargo del profesor Juli PONCE SOLÉ — director de la Escuela Catalana de Administración Pública-, estructurada en torno a tres apartados: la determinación de las bases constitucionales del urbanismo, el estudio de las técnicas concretas que pueden garantizar el derecho a una vivienda asequible y el necesario control judicial del planeamiento urbanístico. En opinión de PONCE SOLÉ, el urbanismo actual debe tener más en cuenta a la ciudadanía, consideración que - según expuso- se debe plasmar en la creación de modelos urbanísticos que consideren tanto la perspectiva cuantitativa y la económica —número de viviendas construidas y precio de las mismas-, como la cualitativa, es decir, su ubicación, los servicios de que disponen, o el nivel de calidad de vida que éstas proporcionan. De hecho, en su intervención destacó la importancia que la ciudadanía otorga actualmente a este tercer factor, lo cual está provocando una eclosión de urbanizaciones cerradas, con la consecuente falta de cohesión social de las ciudades y la aparición de guetos urbanos.

Posteriormente, el ponente aludió al llamado «derecho a la ciudad» en el cual se integran diversos derechos y principios constitucionales tales como el derecho a una vivienda digna, a la libertad religiosa o a la educación, así como el principio de igualdad. PONCE SOLÉ se detuvo en el análisis del derecho recogido en el artículo 47 de la Constitución española y manifestó que

\footnotetext{
* Actividad realizada en el marco del Proyecto de Investigación SEJ 2006/14184 «El derecho constitucional a una vivienda digna y políticas públicas».
} 
este precepto impone a los poderes públicos la necesidad de actuar eficazmente, de tal modo que se otorgue a los ciudadanos una oportunidad realista de conseguir una vivienda - y no tanto que todos los habitantes deban tenerla de hecho-. Además, este derecho vincula en su ejercicio a los agentes privados (por ejemplo, evitando que se lleven a cabo actuaciones tales como el denominado «acoso inmobiliario»). Entre las posibles actuaciones a adoptar por los poderes públicos, el ponente se refirió a las reservas de suelo para VPO como una de las medidas que pueden garantizar mejor la efectividad de ese derecho - afirmación que refrendó evocando su empleo en otros países de nuestro entorno, como Reino Unido, Francia o Estados Unidos - consiguiendo por esta vía el doble objetivo de construir vivienda asequible e integrarla en la ciudad, evitando la segregación urbana.

Por último, PONCE SOLÉ expuso la necesidad de acudir a los mecanismos de control judicial para determinar el cumplimiento de los poderes públicos con la obligación que les impone el artículo 47 de la Constitución. Como nota destacada de este control cabe mencionar la posibilidad de interponer un recurso de amparo ante el Tribunal Constitucional, motivado por la vinculación del derecho a una vivienda digna con otros derechos constitucionales. El ponente concluyó aludiendo a que esta revisión judicial permite también examinar los elementos reglados — como los procedimientos de aprobación de los planes urbanísticos o la necesidad de su motivación-, y discrecionales -desarrollo sostenible, cohesión social e igualdad- presentes en todos los procedimientos de naturaleza urbanística.

II. En la segunda de las ponencias programadas, la profesora Silvia DEL SAZ, en su calidad de Directora General del Suelo de la Comunidad de Madrid, realizó una reflexión crítica sobre la importancia de las políticas del suelo en la configuración de las ciudades, considerando especialmente el clima de inseguridad jurídica existente en el Derecho urbanístico español.

La profesora DEL SAZ citó como factor principal de esta inseguridad jurídica la diversificación del Derecho urbanístico en tres elementos: su marco normativo - competencia exclusiva autonómica en la que sin embargo inciden diversas competencias estatales-, el planeamiento - competencia de los Ayuntamientos pero con intervención autonómica en la aprobación definitiva-, y la ejecución o aplicación de los planes — que puede llevarse a cabo tanto por la iniciativa pública como por los particulares-; lo que conlleva la interrelación de una gran variedad de sujetos competentes en las distintas etapas del urbanismo. Unido a esto, la ponente criticó la falta de estabilidad de las normas y, más concretamente, que en ciertos casos las modificaciones legislativas están exclusivamente motivadas, según sus palabras, por el color político del Gobierno, y no en función del interés general.

Partiendo de lo dicho, y tras exponer el triple objetivo de la política del suelo - conseguir suelo transformado, preparado para su uso urbanístico; 
mantener los terrenos con valores dignos de protección, y lograr un desarrollo urbanístico sostenible-, la ponente manifestó la necesidad de orientar la preocupación política hacia la disminución del valor de mercado de la vivienda en cuanto producto final y no exclusivamente del suelo, que constituye un factor más de los que intervienen en ella. El Derecho español regula diversas clases y categorías de suelo, a las que se vinculan determinados destinos urbanísticos; y cada tipo de suelo soporta un nivel distinto de presión especulativa, siendo mayor el del suelo de uso residencial. Esta expectativa de lucro es una de las causas del alto precio de la vivienda, a la cual se unen otros factores, como la llamada cultura de la propiedad — frente a la del alquiler-, el sistema de ayudas fiscales al préstamo hipotecario o la propia coyuntura económica. Todos estos factores, según la opinión de DEL SAZ, avalan la afirmación anterior de la complejidad de elementos que intervienen en el precio de la vivienda.

Como conclusión a su intervención, la ponente propuso una serie de medidas de política legislativa para reducir la tendencia al alza del precio de la vivienda, entre las que destacó el establecimiento de un límite al precio final del suelo - al estilo de lo que sucede en las VPO-, el incremento de la oferta de suelo finalista - transformado para soportar la urbanización y posterior edificación-, o la agilización de los plazos que rigen el planeamiento y la ejecución de los planes urbanísticos.

III. En la tercera de las ponencias. El Justicia de Aragón, Fernando GARCÍA VICENTE, abordó desde una perspectiva menos técnica la importancia del planeamiento urbanístico en la consecución de ciudades más acordes con las necesidades de sus habitantes. En este sentido, GARCía VICENTE destacó la importancia de la elaboración y ejecución de los planes para conseguir un modelo de ciudad en el que tanto el destino del suelo como otras prescripciones generales se adecúen a los requisitos de habitabilidad de las ciudades - como la facilidad de tránsito por las vías públicas, asegurada con la eliminación de las barreras arquitectónicas o la instalación de ascensores en las viviendas-, y permitan prever las inversiones necesarias en la ciudad a largo plazo, evitando de esta manera gastos de adaptación posteriores —que habitualmente tienen un mayor coste económico-

Finalmente, el ponente criticó la falta de eficacia de las Administraciones públicas, que impide lograr el objetivo propuesto; y planteó como solución el establecimiento de un régimen que proporcione mayor transparencia en la actividad de los funcionarios públicos y de responsabilidad personal, de tal manera que los ciudadanos puedan reclamar de forma más sencilla contra la incorrecta ejecución de las previsiones del planeamiento.

IV. Ramón Salanova Alcalde, Secretario General Técnico del Departamento de Presidencia y Relaciones Institucionales del Gobierno de Aragón, 
fue el encargado de moderar la mesa redonda de la sesión vespertina de las Jornadas, la cual reunió a María José GoNZÁLEZ ORDOVÁs, profesora titular de Filosofía del Derecho; Julio César TEJEDOR BIELSA, profesor titular de Derecho Administrativo - en la actualidad Director General de Urbanismo del Gobierno de Aragón-; Rosa AZnar Costa, Asesora de vivienda de El Justicia de Aragón; y Fernando LóPEZ RAMÓn, Catedrático de Derecho Administrativo.

Al inicio de la sesión, el moderador realizó una serie de afirmaciones provocadoras relacionadas con la efectividad del artículo 47 de la Constitución española. Parafraseando la proclama marxista «la tierra, de quien la cultiva», SALANOVA ALCALDE propuso la afirmación «la tierra, de quien la reclasifica», la cual, en su opinión, rige actualmente el Derecho urbanístico español. La primera de estas sentencias aspiraba a abolir el derecho de propiedad que privaba a los ciudadanos de poseer las tierras de labor no utilizadas por sus propietarios; mientras que la segunda proclama que los propietarios del suelo no pueden impedir que otros sujetos desarrollen urbanísticamente sus terrenos. Asimismo, el ponente apuntó que la solución al problema de la vivienda en España no podrá ser exclusivamente de técnica legislativa urbanística, puesto que afecta también a la economía nacional y se carece de la necesaria voluntad política para atajar esta lacra, tal y como demuestra el nivel de corrupción e incumplimiento de la normativa por parte de los responsables políticos.

En la primera intervención de la mesa redonda, la profesora GonZÁLEZ ORDOVÁs incidió en la necesidad de afrontar el derecho a la ciudad desde una perspectiva sociológica, partiendo del punto de vista de los ciudadanos. La ponente ofreció un completo recorrido histórico de los modelos urbanísticos nacionales, entre los que destacó el de mancha de aceite, que presenta una centralidad equilibrada fruto del crecimiento orgánico de las urbes; y el de las ciudades cerradas, fruto del afán de seguridad de sus habitantes, que provoca la segregación de ciertos núcleos de la ciudad. El objetivo final que, en opinión de la ponente, deben buscar los diversos modelos de ciudad es que el desarrollo de los mismos produzca urbes en las que sus habitantes puedan caminar entre desconocidos sintiéndose, a la par, seguros y en casa, ideal que fracasa en muchas áreas de nuestro entorno.

Como conclusión, GONZÁlEZ ORDOVÁs manifestó que las técnicas urbanísticas, aunque necesarias para la intervención en la ciudad, se han demostrado insuficientes, por lo que se precisa la integración y coordinación de las diversas políticas con incidencia en esta materia. Asimismo, apuntó que es imprescindible trascender de los planes urbanísticos, otorgando una mayor importancia a la posibilidad de adaptación de las ciudades, tal y como expuso Peter Hall en su libro Ciudades del mañana, opinión que compartió la ponente.

La variedad de los intereses que se encuentran en conflicto sobre las ciu- 
dades es lo que provoca que el urbanismo sea una materia tan compleja. En opinión de TEJEDOR BIELSA ésta es la clave del urbanismo actual, junto a la búsqueda, mediante la especulación, del mayor lucro posible, aspecto coincidente en las actuaciones urbanísticas llevadas a cabo por los particulares y por las propias Administraciones públicas. Siendo esto así, el problema radica en el sistema del urbanismo español y, concretamente, en aspectos como la no imposición de un procedimiento de contratación pública para llevar a cabo las actuaciones urbanísticas — que el ponente calificó como obras públicas-, la posibilidad de suscribir convenios urbanísticos por medio de los cuales se elude todo tipo de control, o la determinación del valor del suelo en función del uso que se vaya a dar al mismo - pese a que el propietario no haya realizado ninguna actuación que le haga merecedor de ese beneficio-. Todos estos aspectos se vinculan con la deficiente tipificación de los delitos urbanísticos y la falsa percepción de la actividad urbanística como ejercicio del derecho de propiedad cuando, en realidad, constituye una operación económica, es decir, vinculada con el derecho de libertad de empresa.

Ante estos problemas el ponente mencionó dos posibles soluciones: la revalorización de la planificación y la gestión urbanística como contrapunto al «todo vale» presente en el urbanismo español, y la reconducción de la falta de liderazgo determinando la autoridad competente en cada caso, y obligándole al ejercicio de la misma, sin dejarse arrastrar por falacias o perezas. Es decir, que impera la necesidad de lograr una voluntad política para que resurja el Derecho urbanístico y de esta manera pueda ser eficaz el derecho a la vivienda y el derecho a la ciudad.

La tercera ponente de la mesa redonda, AZNAR COSTA, analizó en su intervención el modo en el que la cuestión del urbanismo y la vivienda afecta a los ciudadanos en su vida ordinaria; y propuso una serie de soluciones a la misma. Entre estas soluciones destacó la necesidad de un cambio de actitud de las administraciones tanto a nivel de planificación - para facilitar la estabilidad de las bases del urbanismo-, como de coordinación y de agilización de los trámites administrativos — con el fin de simplificar los procedimientos urbanísticos-; la creación de un verdadero patrimonio público del suelo - que funcione como un corrector del sistema, inyectando terrenos al mercado en momentos de alza de los precios-; la búsqueda de un sistema de financiación alternativo para las corporaciones locales; la construcción de más viviendas de protección oficial, y el incentivo a la rehabilitación de las edificaciones ubicadas en los cascos históricos.

El último ponente de la mesa redonda, el profesor LÓPEZ RAMÓN, destacó que de las diversas intervenciones de la jornada se extrae la conclusión de la inexistencia de una fórmula única para solucionar el problema del urbanismo en España. Según su opinión, el precio de la vivienda es alto, pero no descenderá mientras los ciudadanos lo paguen. Además, ciertos modelos y tipologías de viviendas han de ser necesariamente de mayor coste, al igual 
que ocurre con los inmuebles de segunda residencia. El problema real ante el que se debe reaccionar, según LÓPEZ RAMÓN, radica en la existencia de un grupo de excluidos - temporales o permanentes- del sistema, y para ellos es para quienes se precisa la articulación de políticas sociales, de tal modo que les sea posible el acceso a una vivienda, ya sea en propiedad o en alquiler.

Dicho esto, el ponente recalcó que no existe un sistema administrativo que permita contener los precios, ya que la única vía posible — que LóPEZ RAMÓN cifró en la eliminación del mercado a través de la construcción exclusiva de viviendas de protección oficial一, no resulta ni viable ni recomendable, ya que el descenso automático y directo del precio de la vivienda ocasionaría la quiebra de la economía nacional. Finalmente, el ponente añadió que siempre ha sido complicado acceder a la vivienda - por lo que no constituye éste un fenómeno exclusivo de la actualidad-, y concluyó que sólo queda a los ciudadanos buscar el mejor momento para incorporase a este mercado, ya que aguardar a una hipotética mejora del sistema puede convertirse en una espera eterna.

V. El inicio de la segunda jornada estuvo a cargo del profesor Luciano PAREJO ALFONSO, el cual realizó una interesante exposición sobre los aspectos más destacados del proyecto de Ley del Suelo estatal. Comenzó su intervención analizando la triple motivación del proyecto: la degradación de la cultura urbanística española y del régimen de propiedad; la utilización del urbanismo como una política sectorial orientada a la obtención de suelo por parte de los poderes sociales -y por lo tanto de recursos financieros-; y la reducción del papel de la Administración pública a una mera instancia pasiva controladora de la actividad urbanística. A partir de estos datos, PAREJO ALFONSO aludió al objetivo final del Proyecto, es decir, refundar el urbanismo español en el interés general, utilizando para ello medidas de policía y de ordenación de la actuación urbanística y territorial, e intentando asegurar la estabilidad normativa y la seguridad jurídica, todo ello sin utilizar técnicas urbanísticas — tales como la clasificación o la gestión del suelo- ni incluir disposiciones que precisaran la adaptación de las normas autonómicas, puesto que el Estado no es competente en materia de urbanismo.

Posteriormente, el ponente se refirió a la necesidad de deslindar las perspectivas objetiva y subjetiva del derecho de propiedad - reguladas en los apartados 2 y 3 del artículo 33 de nuestra Constitución-, con el fin de posibilitar la ejecución del planeamiento tanto por el propietario del terreno como por otro actor - público o privado- . La razón de esta interpretación radica en los diversos derechos que inciden en el suelo. Por un lado el derecho de propiedad impide que se prive de su posesión al titular de un terreno; sin embargo, cuando media un desarrollo urbanístico y se genera un plusvalor -que no es fruto de la actuación del propietario-, éste se regirá por el derecho de libertad de empresa. 
VI. En la segunda de las ponencias, el Magistrado del Tribunal Supremo José Manuel BANDRÉs SÁNCHEZ-CRUZAT, llevó a cabo una caracterización del urbanismo constitucional, determinando la situación de crisis en la que se encuentra actualmente.

El ponente inició su intervención denunciando la existencia de sendos informes de la Comisión de Derechos Humanos de la ONU y del Parlamento Europeo sobre la vulneración de derechos por nuestro ordenamiento jurídico urbanístico, lo cual constituye, según el ponente, una situación de crisis sin precedentes en nuestra tradición normativa. La competencia de esos organismos internacionales para analizar nuestro Derecho proviene tanto de los principios generales del Derecho, como del estatuto de ciudadanía europeo; de hecho, las técnicas jurídicas usadas para lograr un uso racional del suelo y los instrumentos de planeamiento, inciden directamente sobre la ciudad y la convivencia.

Posteriormente, el discurso de BANDRÉs SÁNCHEZ-CRUZAT se centró en un interesante y completo estudio de las singularidades del urbanismo desde la óptica constitucional, aderezando sus manifestaciones con la mención de los preceptos legales concretos que fundamentan su caracterización. Entre otras condiciones, el ponente dio relevancia a que se trata $-\mathrm{O}$ al menos debe tratarse- de un urbanismo social, que persiga el interés general, sostenible —ambiental, económica y socialmente-, plural, democrático, local y transparente - de tal manera que permita a los ciudadanos controlar la actividad urbanística del Gobierno y comprender los procedimientos urbanísticos, para lograr un urbanismo eficiente, revisando los tiempos y plazos que operan en él一.

El Magistrado concluyó estableciendo el desafío del urbanismo en el doble objetivo de lograr la estabilidad y perdurabilidad de las ciudades para las nuevas generaciones (evitando la degradación de los cascos históricos) y de solucionar, ya desde ahora, el problema que un futuro incremento de población puede suponer para la adquisición de una vivienda.

VII. Como brillante colofón de estas Jornadas, se pudo disfrutar de la intervención de Antonio VerCHER NOGUERA, Fiscal de Sala coordinador de Medio Ambiente y Urbanismo del Tribunal Supremo, que disertó sobre los delitos urbanísticos.

A lo largo de su intervención, VERCHER NOGUERA desarrolló una exégesis del artículo 319 del Código Penal, tipificador de los delitos contra la ordenación del territorio, complementada con la mención de un amplio elenco de sentencias del Tribunal Supremo que refrendaban las tesis defendidas por el ponente. Uno de los problemas que planteó fue la determinación del bien jurídico protegido por el artículo 319. La dicción literal del apartado segundo de dicho precepto parece indudablemente referida al medio ambiente, pero 
el primer apartado del mismo enumera una serie más amplia de materias, entre las que se integra también el patrimonio cultural, por lo que carecemos de una determinación precisa de su elemento objetivo. Otro de los interrogantes suscitados fue el ámbito subjetivo del tipo delictivo, cuestión que, en opinión de VERCHER NOGUERA, debe resolverse con una interpretación amplia, tal y como establece reiterada jurisprudencia, considerando las menciones de «constructor, promotor o técnico director» en sentido genérico, como referidas a cualquier sujeto que intervenga en esa actuación urbanística ilícita.

Más allá de la literalidad del artículo 319, el ponente abordó diversos problemas prácticos planteados en los tribunales, tales como la dificultad de determinar cuándo una casa prefabricada se califica como edificio permanente -en parte resuelta con la exigencia de un certificado administrativo de movilidad-, el recurso a los convenios urbanísticos como vía de elusión de las órdenes de demolición o de las normas urbanísticas que menos se adecúan a los intereses de los promotores o de los Ayuntamientos - modificando el planeamiento urbanístico de forma discrecional-, la construcción de inmuebles contrarios a un plan no publicado - lo cual puede suponer un delito de prevaricación por omisión-, y la aplicación del tipo de prevaricación por omisión como respuesta a otras infracciones tales como la inactividad de los miembros del consistorio al no clausurar establecimientos de ocio nocturno que notoriamente superan el nivel de ruido permitido por la legislación aplicable.

Como conclusión, y reconociendo la imposibilidad de plasmar en estas líneas la abundancia y variedad de ideas e inquietudes suscitadas en las diversas intervenciones, cabe auspiciar la mejora en la plasmación práctica de los derechos a la vivienda y la ciudad, reconociendo las necesidades de los ciudadanos y estudiando conjuntamente las diversas materias que inciden en el urbanismo. En definitiva, foros como estas IV Jornadas Constitucionales resultan de indudable interés, tanto para juristas especializados en el campo del urbanismo y la vivienda como para los ciudadanos en general, interesados en la complicada tarea de hacer efectivos los derechos constitucionales. 